\title{
E. Martin Meunier, Robert Mager, (dirs.), « La religion au Québec - Regards croisés sur une intrique moderne »
}

Globe, Revue internationale d'études québécoises, 2007-2008, 315 p.

\section{Géraldine Mossière}

\section{(2) OpenEdition \\ Journals}

Édition électronique

URL : http://journals.openedition.org/assr/21620

DOI : $10.4000 /$ assr. 21620

ISSN : $1777-5825$

Éditeur

Éditions de l'EHESS

Édition imprimée

Date de publication : 31 décembre 2009

ISBN : 978-2-7132-2218-4

ISSN : 0335-5985

Référence électronique

Géraldine Mossière, «E. Martin Meunier, Robert Mager, (dirs.), «La religion au Québec - Regards croisés sur une intrique moderne » », Archives de sciences sociales des religions [En ligne], 148 | octobredécembre 2009, document 148-93, mis en ligne le 15 novembre 2012, consulté le 21 septembre 2020. URL : http://journals.openedition.org/assr/21620 ; DOI : https://doi.org/10.4000/assr.21620

Ce document a été généré automatiquement le 21 septembre 2020.

(C) Archives de sciences sociales des religions 


\section{E. Martin Meunier, Robert Mager, (dirs.), « La religion au Québec - Regards croisés sur une intrique moderne »}

Globe, Revue internationale d'études québécoises, 2007-2008, 315 p.

\section{Géraldine Mossière}

\section{RÉFÉRENCE}

E. Martin MEUNIER, Robert MAGER, (dirs.), « La religion au Québec - Regards croisés sur une intrique moderne ", Globe, Revue internationale d'études québécoises, 2007-2008, $315 \mathrm{p}$.

148-93

Dans une réflexion qui aurait pu ouvrir la revue mais qui, de façon surprenante, la clôt, le célèbre sociologue de la religion québécois Raymond Lemieux pose la problématique : « dans un sondage effectué en 2002 auprès de jeunes Canadiens de toutes confessions et de toutes les provinces, les répondants québécois, dont $72 \%$ disaient "s'identifier à la tradition catholique" y ont régulièrement montré des taux d'adhésion inférieurs à ceux de toutes les autres catégories.»(p.226). Ainsi est posé le constat qui inspire l'ensemble des contributions de la revue et qu'exprime clairement le sociologue Reginald Bibby « la sécularisation n'a pas tué la religion » (p. 175). Si l'observation n'est pas exclusive au Québec, la province se distingue cependant par une longue période de tutelle cléricale communément appelée « Grande Noirceur » à laquelle une désaffection du religieux aussi profonde que soudaine a fait place au cours des années soixante-dix, rupture qualifiée de "révolution tranquille». Au point que, pour l'opinion publique comme pour les chercheurs en sciences sociales, évoquer la question de la religion a longtemps revêtu un caractère suspect, voire tabou. Comment le fait religieux 
s'articule-t-il aujourd'hui aux enjeux sociaux et politiques et à un imaginaire symbolique en perpétuelle reconstruction dans une société présentée comme l'une des «plus rapidement sécularisées de l'Occident » (p. 226) ?

C'est à cette question que les douze contributions et deux notes critiques de ce numéro spécial sur la religion au Québec tentent de répondre. À défaut de proposer un portrait exhaustif, ou du moins de recouvrir les différents aspects d'un thème relativement nouveau dans le champ des sciences sociales québécoises longtemps accaparées par la question ethnique, la revue présente une variété d'articles comme autant de perspectives, parfois de points de vue, sur une réalité encore abordée d'un point de vue subjectif, comme ne manque pas de le souligner avec honnêteté et réflexivité scientifique, la théologienne Anne Fortin. L'approche est donc multidisciplinaire, fidèle au titre de ce numéro spécial et les disciplines d'origine des auteurs sont aussi diverses que leurs contributions: philosophe, juriste, sociologue, théologien, historien composent autant d'essais, de réflexions scientifiques, d'analyses littéraires, d'études ethnographiques ou juridiques. Chacun à sa manière s'interroge sur la nouvelle sensibilité religieuse québécoise, sa portée sur l'imaginaire de la province et les alternatives qui tentent de lui prendre le pas: comment le rejet du phénomène religieux a-t-il affecté les caractéristiques éthiques et communautaires de la société québécoise? Sous quelles conditions un retour du religieux est-il envisageable? (Gabriel Malenfant). Le religieux a-t-il le monopole de la transcendance et du sens, l'œuvre d'art ne peut-elle pas, elle aussi, interroger et nourrir cette quête humaine? (Daniel Tanguay).

3 Le philosophe Daniel Tanguay et l'historien Éric Bedard s'accordent à montrer que la production culturelle québécoise révèle l'ambiguïté du rapport au religieux des Québécois, entre le trauma né de la longue hégémonie de l'institution catholique d'une part, et le vide identitaire et culturel qui a suivi son déclin d'autre part. Les récits de pèlerins québécois à Saint-Jacques-de-Compostelle, rapportés par Caroux et Rajotte, traduisent en effet une quête de filiation qui, tout en rompant avec un "passé cléricoconservateur, vise à redonner sens à un présent en déficit symbolique. » (p. 53). Cette reconfiguration de la tradition à l'aide " d'autres jaillissements religieux ou sources de sagesse » (p. 72) vise en réalité à répondre à un "présentisme» perçu comme anxiogène. L'étude quantitative de Bibby clarifie cette ambivalence : les recensements et sondages effectués dans la province démontrent que si les Québécois persistent à s'identifier comme catholiques, leur pratique religieuse reste limitée ou sélective et leur attitude encore très critique vis-à-vis de l'Église et de ses prises de position.

Il ressort donc que la religion reste présente et centrale dans le quotidien et l'identité des Québécois, le sociologue Bibby y voit d'ailleurs, peut-être un peu hâtivement, une nouvelle opportunité pour l'Église catholique. C'est, en effet, sans compter les nouvelles ressources religieuses introduites par les nouveaux arrivants. Or, seules deux contributions abordent la question de la religion sous l'angle de l'immigration, ce qui semble peu compte tenu de l'importance du phénomène dans une province qui se veut également une terre d'accueil. Soulignant que l'islam compte pour la deuxième plus importante religion non chrétienne au Canada, Mouloud Haddad démontre comment cet islam s'inscrit dans un espace francophone transnational. Il se limite toutefois au cas spécifique de deux confréries soufies présentes à Montréal. Louis Rousseau, quant à lui, s'intéresse à des immigrants originaires de l'Afrique noire appartenant à des Églises évangéliques de type pentecôtistes et installées au Québec depuis une quinzaine 
d'années. À l'aide d'une approche ethnographique, il tente de comprendre comment la "référence ethno-religieuse " intervient dans leur stratégie d'intégration sociale et examine « les traits de la culture d'accueil qu'ils sont disposés à accepter et ceux qu'ils refusent pour eux et pour leurs enfants » (p. 209).

5 À l'inverse, l'influence de ces religiosités importées n'est abordée que sous l'angle juridique des accommodements légaux que la province doit organiser pour s'y adapter. En discutant les débats qui ont entouré l'application de ces mesures dans la province, le sociologue Bock Côté démontre que les enjeux dépassent en réalité ceux de la laïcité et qu'ils touchent à la délicate "question de l'identité nationale et de sa capacité à s'imposer comme norme fondatrice pour l'ensemble de la communauté politique » (p. 95). Le sociologue insiste sur l'attachement des Québécois à leur « communauté de mémoire et de culture » (p. 111), de sorte que son essai amène le lecteur à s'interroger : le nationalisme québécois pourrait-il être une nouvelle religion pour certains Québécois? La comparaison fort intéressante que David Koussens établit entre les décisions juridiques prises en France et au Québec sur le port de signes religieux répond à la question: si le problème divise encore l'opinion publique au Québec, l'application de la décision de la Cour Suprême du Canada " promeut l'idée que l'école est un espace de redéfinition des valeurs partagées par les citoyens» (p.115). Le numéro spécial de la revue Globe intéressera ceux qui s'interrogent sur le maintien et le dynamisme de religiosités dans une société récemment et brutalement sécularisée qui repense son identité au temps présent, entre nation, religion et globalisation. 